\title{
Perfil ideal de competência profissional de gestores da área de saúde
}

\author{
Lydia Maria Pinto Brito \\ Mestre em Socilogia e doutora em Educação pela UFC.Professora do Mestrado em Administração da UNP. \\ lydiampbrito@yahoo.com.br
}

José Luciano Braga

Mestre em Administração pela PUC-Rio. Consultor Internacional

bragajl@terra.com.br

RESUMO: A questão de pesquisa do presente estudo consistiu: qual a percepção dos profissionais, gestores e lideranças da área de saúde sobre o perfil ideal de competência profissional que os ocupantes de postos de comando deveriam ter? O objetivo geral, portanto, consistiu em levantar a percepção dos pesquisados sobre perfil ideal de competência profissional para o exercício de atividades gerenciais na área de saúde. 0 referencial teórico fundamentou-se principalmente em Galer, Vriesendorp e Ellis (2005), Bitencourt (2001, 2006), Le Boterf (2003), Heifetz (1999), Ruas (2005), Baldwin, Rubin, e Bommer (2008), dentre outros. A pesquisa de natureza descritiva consistiu numa Survey que envolveu 450 profissionais de 18 instituições públicas e privadas da área de saúde, em sua maioria médicos, enfermeiros e farmacêuticos, ocupantes dos cargos de coordenador, diretor, gerente, chefe de serviço/setor, supervisor e técnicos, de hospitais, órgãos do governo e cooperativas de classe das cidades de Fortaleza, Natal e Recife. Os resultados revelaram a percepção dos pesquisados sobre perfil de competência profissional ideal para o exercício de atividades gerenciais na área de saúde com destaque para os atributos relacionados ao conhecimento e habilidade de planejamento estratégico e operacional, habilidade de liderança e atitude ética.

PALAVRAS CHAVES: Perfil Ideal; Competência Profissional; Saúde.

ABSTRACT: The research issue of this present study constituted the following: what is the perception of professionals, managements and leaders of the health area about the professional competence ideal profile who those in command position should have? The general objective, therefore, consisted in obtain the perception of the researched ones about the of professional competence ideal profile for the exercise of managerial activities in the area of health. The theoretical referential was based principally in Galer, Vriesendorp and Ellis (2005), Bitencourt (2001,2006), Le Boterf (2003), Heifetz (1999), Ruas (2005), Baldwin, Rubin, and Bommer (2008), among others. The descriptive nature research consisted in a survey that involved 450 professionals from 18 public and private institutions from health area, most of they are doctors, nurses and pharmacists, which were in the positions of coordinator, director, manager, chief of service/of sector, supervisors and technicians of hospitals, govern and class cooperative enterprises from the cities of Fortaleza, Natal and Recife. The results revealed the perception of the researched ones about the professional competence ideal profile for the exercise of managerial activities in the health area emphasizing the attributes related to the knowledge and ability of operational and strategic planning, leadership ability and ethic attitude.

KEYWORDS: Ideal Profile; Management Competence; Health.

\section{INTRODUÇÃO}

A reflexão sobre a gestão de competências organizacionais / essenciais intensificada nos anos 1990 (HAMEL, PRAHALAD, 1995) tem como desdobramento: num primeiro momento a elaboração de conceitos sobre perfis de competências profissionais nos Estados Unidos (BAND, 1997; FLANNERY, HOFRICHTER e PLATTEN, 1997), na Europa (ZARIFIAN, 2001, PERRENOUD, 2002; LE BOTERF, 2003) e no Brasil (RIOS, 1993; PICARELLI FILHO, 1997; WOOD Jr., 1997; REZENDE, 2000; FLEURY, 2001; DUTRA, 2002, GRAMIGNA, 2002), dentre outros; e num segundo momento para gerenciamento da implantação do modelo nas organizações, o desenvolvimento de competências gerenciais (GALER, VRIESENDORP E ELLIS, 2005; BITENCOURT, 2001, 2006; HEIFETZ, 1999; RUAS, 2005; BALDWIN, RUBIN, E BOMMER, 2008), que articulassem os papéis de gestor e liderança para condução do processo com maior eficácia, num contexto caracterizado pelo aumento da turbulência, instabilidade econômica, pelas pressões da comunidade, ameaça de concorrentes, necessidade de identificar novas oportunidades no mercado e na sociedade. Neste ambiente, identificar, desenvolver e gerenciar competências que agregassem valor aos negócios passou a ser uma demanda fundamental. 
Assim, a área de saúde também assume nova dinâmica articulando "desde consultórios e clínicas, hospitais, laboratórios e centros de diagnóstico, até empresas de assistência médica, seguro-saúde, cooperativa e autogestão (...) passando a exigir uma gestão empresarial nessas organizações" (YAMAMOTO, 2002, p.15) e passa a construir um conhecimento em sintonia com as modernas práticas de gestão, em construção na atualidade (PORTER e TEISBERG, 2007), tendo como principal foco reformar de fato o sistema para agregar valor para todos os cidadãos, inclusive os de baixa renda, mediante a formulação de estratégias focadas no processo de aprendizagem e obtenção de resultados sociais relevantes. (PORTER e TEISBERG, 2007, p.25)

Desta forma, a questão de pesquisa do presente estudo consistiu em: qual a percepção dos gestores e lideranças da área de saúde sobre o perfil ideal de competência profissional que os ocupantes de postos de comando deveriam ter? O objetivo geral, portanto, consistiu em levantar a percepção dos pesquisados sobre perfil ideal de competência profissional para o exercício de atividades gerenciais na área de saúde. O referencial teórico fundamentou-se principalmente em Galer, Vriesendorp e Ellis (2005), Bitencourt (2001, 2006), Le Boterf (2003), Heifetz (1999), Ruas (2005), Baldwin, Rubin, e Bommer (2008), dentre outros.

A pesquisa de natureza descritiva consistiu numa Survey que envolveu 450 profissionais de 18 instituições públicas e privadas da área de saúde, em sua maioria médicos, enfermeiros e farmacêuticos, ocupantes dos cargos de coordenador, diretor, gerente, chefe de serviço/setor, supervisor e técnicos de hospitais, órgãos do governo e cooperativas de classe das cidades de Fortaleza, Natal e Recife, participantes de 15 turmas dos cursos: (a) Programas de Desenvolvimento de Liderança (PDL) - promovidos pela Escola de Saúde Pública (ESP) do Estado do Ceará; e (b) cursos de Administração Hospitalar - promovidos por universidades dos Estados do Ceará, Rio Grande do Norte e Pernambuco.

A escolha do programa de PDL para realização da pesquisa deve-se a sua importância para a área de saúde, considerando abrangência, capilaridade, conteúdo e avaliações. É importante registrar que o curso de PDL, dado em programas específicos ou como disciplina dos cursos de administração hospitalar tem como objetivo geral melhorar as competências de liderança e gerência dos participantes, capacitando-os para agregar valor à prática nas relações com o cliente interno e externo. Este adota a abordagem histórica cultural de Vygotsky (1999 2001). O conteúdo programático é composto de conceitos, modelos e práticas de aprendizagem, liderança e gerência. O programa tem duração média de 30 horas e é desenvolvido mediante exposições teóricas e conceituais, debates, estudos de caso, exercícios e trabalhos em grupo. A avaliação de reação realizada por alunos, facilitador e coordenadores do curso apresenta excelentes resultados.

O presente artigo é composto dos seguintes itens: 1. Referencial Teórico; 2. Metodologia; 3. Resultados Obtidos e Considerações provisórias.

\section{REFERENCIAL TEÓRICO}

Dependendo de cada autor variam as taxonomias para definir os atributos das competências relacionadas à gerência e liderança.

\subsection{Gerência e liderança}

Band (1997) ao definir as competências críticas para revolucionar as organizações sinaliza, dentre outros, as novas habilidades da liderança, para agregar valor: previsão e visão do futuro, empowerment, coerência de valores, autocompreensão.

Galer, Vriesendorp e Ellis (2005) propõem uma estrutura para gerentes que lideram, articulando os papéis de liderança e gerência.

A liderança tem uma dimensão mais ampla e alinha potencial, condições internas e externas e interesses pessoais com necessidades organizacionais, tendo como focos:

- explorar e diagnosticar o ambiente interno e externo - que consiste em perceber a realidade pessoal, da equipe, da organização; conhecer a si mesmo, seus valores, seus pontos fortes e fracos; conhecer as aspirações e interesses dos outros membros de seu grupo de trabalho; e identificar as necessidades dos clientes, parceiros e concorrentes e os desafios organizacionais e tem como produto principal o fato de que a organização passa a dispor de uma visão superior das tendências de seu ambiente interno e externo, baseada num conhecimento constantemente atualizado;

- focalizar - ou seja, identificar prioridades; concentrar a atenção do grupo nos desafios críticos; definir em equipe a missão/ propósito do trabalho do grupo em relação com a missão organizacional; engajar o grupo de trabalho no "pensar estratégico" e que tem como produto principal missão, estratégia e prioridades, claramente compreendidas por todos e usadas para direcionar o trabalho; 
- alinhar e mobilizar o pessoal - criar e coordenar times onde se faz necessário; fazer a coordenação dos objetivos organizacionais com os objetivos individuais e dos grupos de trabalho; mobilizar (buscar) recursos de fontes externas e internas, tendo como produto principal - os integrantes do grupo de trabalho dispõem de planos que estão alinhados de forma a dar suporte às estratégias de trabalho do grupo, e têm motivação e recursos suficientes para levar a cabo estes planos; e

inspirar e motivar a equipe - demonstrar fé e confiança no grupo; proporcionar, ao grupo, desafios claros, feedback e suporte; dar apoio à criatividade, inovação e aprendizagem; passar integridade nas interações, cujo produto principal - os integrantes do grupo de trabalho estão comprometidos com a missão do trabalho do grupo e com a inovação e aprendizagem contínuos. Todos estão utilizando suas habilidades de forma total. (GALER et al, 2005, p.178).

Já a gerência alinha as partes internas da organização, mediante ações de: - planejamento - onde são estabelecidos os objetivos organizacionais de curto prazo e metas de desempenho; elaborados os planos anuais e plurianuais; e alocados os recursos financeiros, humanos e materiais e que tem como resultado - a organização/área passar a dispor de resultados pretendidos, recursos alocados e de um plano operacional;

- organização de recursos - para desenvolver processos (formas) de trabalho; assegurar estrutura clara de responsabilidade e autoridade; e definir sistemas eficazes para gerência de recursos humanos, finanças, logística, garantia de qualidade, operações, informação e marketing que tenham como objetivo dotar a organização de estrutura, sistemas e processos funcionais, que possam garantir operações eficientes e equipes estão organizadas e conscientes de suas responsabilidades e expectativas no trabalho;

implementação e execução do trabalho - ao proporcionar conhecimentos e habilidades para desenvolver os talentos; dar desafios, feedback e apoio; integrar sistemas e coordenar o fluxo de trabalho; e equilibrar demandas e decisões concorrentes garantindo a eficiência organizacional; e finalmente

- monitoração e avaliação de resultados - monitorando o progresso frente aos planos, proporcionando feedback e fazendo ajustes, identificando mudanças requeridas e melhoramentos, desenvolvendo processos, rotinas e ferramentas melhoradas de trabalho e aprendendo continuamente e usar o conhecimento adquirido com o monitoramento e a avaliação. (GALER et al, 2005, p.178).

Desta forma, passa a ser um dos grandes desafios organizacionais o desenvolvimento de forma articulada de competências que contribuam para formação de gestores líderes, tais como: (a) gerenciais - planejamento, organização de recursos, implementação e execução do trabalho e monitoração dos resultados; e (b) de liderança - explorar, focalizar, alinhar e mobilizar o pessoal, e inspirar e motivar a equipe.

\subsection{Competência profissional}

Para Le Boterf (2003) a competência na dimensão do trabalho significa possuir determinados tipos de saberes para administrar uma situação profissional complexa.

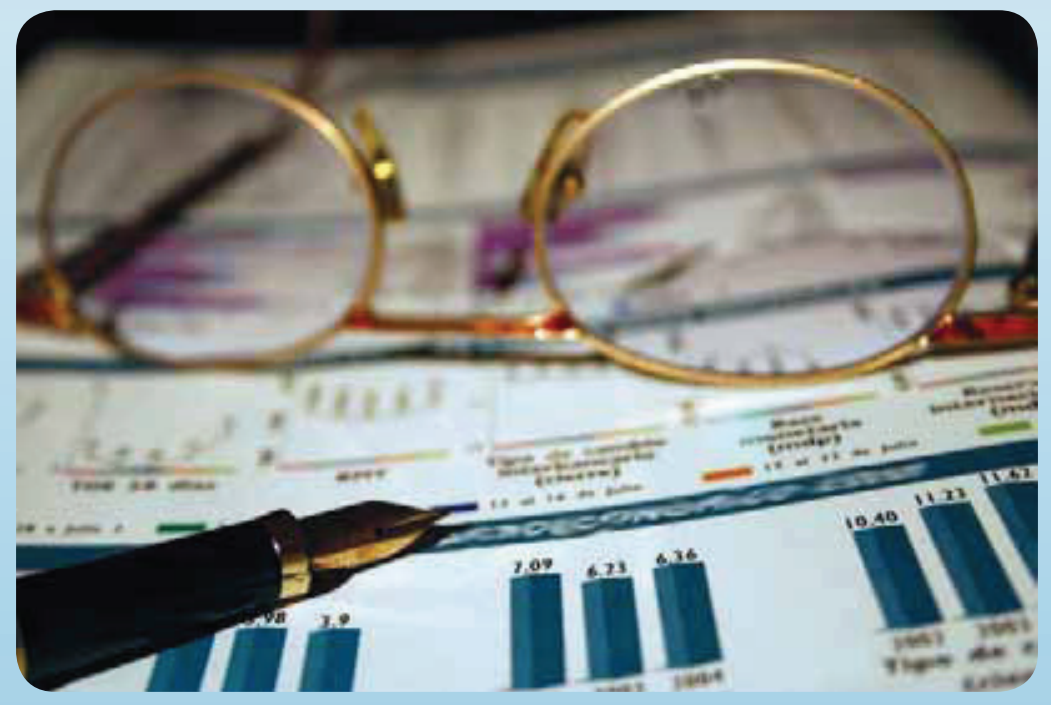




\section{Quadro 1 - Saberes profissionais}

\begin{tabular}{|c|c|}
\hline Saberes & Definições \\
\hline $\begin{array}{l}\text { Saber agir e reagir com } \\
\text { pertinência }\end{array}$ & $\begin{array}{l}\text { - saber o que fazer; } \\
\text { - saber ir além do prescrito; } \\
\text { - saber escolher na urgência; } \\
\text { - saber arbitrar, negociar, decidir; } \\
\text { - saber encadear ações de acordo com a finalidade. }\end{array}$ \\
\hline $\begin{array}{l}\text { Saber combinar recursos } \\
\text { e mobilizá-los em um } \\
\text { contexto }\end{array}$ & $\begin{array}{l}\text { - saber construir competências a partir de recursos; } \\
\text { - saber tirar partido não somente de seus recursos incorporados (saberes, } \\
\text { saber-fazer, qualidades), mas também dos recursos de seu meio. }\end{array}$ \\
\hline Saber transpor & $\begin{array}{l}\text { - saber memorizar múltiplas situações e soluções-tipos; } \\
\text { - saber distanciar-se, funcionar "em dupla direção"; } \\
\text { - saber utilizar seus metaconhecimentos para modelizar; } \\
\text { - saber determinar e interpretar indicadores de contexto; } \\
\text { - saber criar as condições de transponibilidade com o auxílio de } \\
\text { esquemas transferíveis. }\end{array}$ \\
\hline $\begin{array}{l}\text { Saber aprender e aprender } \\
\text { a aprender }\end{array}$ & $\begin{array}{l}\text { - saber tirar as lições da experiência; saber transformar sua ação em } \\
\text { experiência; } \\
\text { - saber descrever como se aprende; } \\
\text { - } \text { - saber agir em circuito duplo de aprendizagem. }\end{array}$ \\
\hline Saber envolver-se & $\begin{array}{l}\text { - saber envolver sua subjetividade; } \\
\text { - saber assumir riscos; } \\
\text { - saber empreender; } \\
\text { - ética profissional. }\end{array}$ \\
\hline
\end{tabular}

Fonte: Le Boterf (2003, p.92)

A competência profissional, portanto, implica em ação pertinente, mobilização e combinação de recursos, conexão entre situações, aprendizado e envolvimento com soluções e resultados para os problemas organizacionais.

\subsection{Competência Gerencial}

Moreira et al (1997 entende que as competências gerenciais abrangem dimensões: técnica, administrativa, psicossocial e política. A dimensão técnica "compreende o conhecimento específico dentro da especialidade da área de atuação" (MOREIRA et al, 1997, p.14); a dimensão administrativa refere-se ao planejamento, organização, coordenação e acompanhamento das atividades que Ihe são destinadas; a dimensão psicossocial é focada na dinâmica dos inter-relacionamentos e a dimensão política refere-se ao exercício do poder, ao grau de autonomia e decisão e a capacidade de influência nas ações da empresa.

Oderich (2005) in Ruas (2005) estabelece como componentes do perfil do gestor na atualidade: visão sistêmica e estratégica, domínio pessoal, capacidade de trabalhar em equipe, habilidades humanas e interculturais, criatividade, flexibilidade, capacidade de inovação, comportamento ético e capacidade de aprender, de liderar e educar". (ODERICH in RUAS, 2005, p.94).

O modelo de Heifetz (1999) aponta para três componentes na composição do perfil de competência profissional: conhecimentos, habilidades e valores que se concretizam em atitude. 
Quadro 2 - Sistema de Liderança de Heifetz (1999)

\begin{tabular}{|c|c|c|}
\hline Conhecimento & Habilidades & Valores \\
\hline $\begin{array}{l}\text { - Análise pessoal e de } \\
\text { contexto } \\
\text { - Contexto para um } \\
\text { processo sistemático de } \\
\text { trabalho de adaptação } \\
\text { - Contexto para a } \\
\text { intervenção } \\
\text { - Conhecimento de temas, } \\
\text { processos, instituições e } \\
\text { políticas relevantes }\end{array}$ & $\begin{array}{l}\text { - } \text { Refletir e analisar } \\
\text { - } \text { desempenciar-se do papel } \\
\text { - Saber ouvir } \\
\text { - Impor limites e saber lidar com } \\
\text { eles } \\
\text { - } \text { Autoridade } \\
\text { - Criar e aproveitar situações } \\
\text { - Orquestrar o conflito e a } \\
\text { - } \text { diversidade } \\
\text { - Criatividade e curiosidade } \\
\text { - Coragem e resistência }\end{array}$ & $\begin{array}{l}\text { - Aumento da capacidade de } \\
\text { adaptação do sistema social } \\
\text { - Paixão pela sabedoria } \\
\text { - Exame dos valores } \\
\text { - Dilemas morais da liderança }\end{array}$ \\
\hline
\end{tabular}

Fonte: Adaptado de Heifetz (1999)

Competência gerencial, portanto envolve conceitos relacionados à articulação de liderança e gerência: aptidão, formação, ação pertinente, mobilização e combinação de recursos, conexão entre situações e aprendizado. Supõe o envolvimento com soluções e resultados que agreguem valor para a resolução dos problemas organizacionais nas dimensões: administrativa, psicossocial e política.

Desta forma, pode-se definir para o presente estudo, a taxonomia que define o perfil de competência gerencial como a descrição do conjunto de: conhecimentos - saber conceitual, habilidades - componente comportamental que se refere à capacidade de aplicar os conhecimentos, ou seja, de saber fazer, e atitudes - componente comportamental que se refere ao querer fazer a partir do desejo e motivação pessoal, que permite a empresa manter-se atualizada e projetar para o futuro a eficácia de sua competência essencial (BRITO 2005, p.61).

Para a presente pesquisa considerou-se que as atitudes refletem os valores do indivíduo, enquanto construtos que representam mentalmente objetivos humanos básicos e universais e que orientam a ação dos indivíduos.

\section{METODOLOGIA}

A pesquisa de natureza qualitativa caracteriza-se como com relação aos objetivos como descritiva. Foi realizada uma survey com 450 profissionais de 18 instituições da área de saúde, em sua maioria: médicos, enfermeiros e farmacêuticos, ocupantes dos cargos de coordenador, diretor, gerente, chefe de serviço/ setor, supervisor e técnicos de hospitais públicos e privados, órgãos do governo e cooperativas de classe das cidades de Fortaleza, Natal e Recife.

A coleta de dados aconteceu em dois momentos principais: $1^{\circ}$. momento -utilizou grupos de foco (COOPER e SCHINDLER,2003,p.133) com lideranças para identificação e definição dos atributos do Perfil de Competência Gerencial: conhecimentos, habilidades e atitudes / valores, seguida de análise de conteúdo (FLICK, 2004, p.202); e $2^{\circ}$.momento - de natureza quantitativa realizou a aplicação de questionários para validação e priorização dos atributos definidos anteriormente.

$1^{\circ}$. momento - foram realizadas discussões em grupos de foco com 450 profissionais participantes de 15 turmas dos cursos: (a) Programas de Desenvolvimento de Liderança (PDL) - promovidos pela Escola de Saúde Pública (ESP) do Estado do Ceará; e (b) cursos de Administração Hospitalar - promovidos por universidades dos Estados do Ceará, Rio Grande do Norte e Pernambuco para identificação e definição dos atributos que deveriam compor o Perfil de Competência profissional dos gestores da saúde. Um "grupo de foco é um painel de pessoas, lideradas por um moderador treinado [no caso o pesquisador] que se reúne [com os pesquisados] por um período de 90 minutos a duas horas" (COOPER e SCHINDLER, 2003, p.133).

O papel do moderador é utilizar os princípios da dinâmica de grupo para focar ou guiar o grupo na troca de idéias, sentimentos e experiências com relação a um tópico específico, que no caso da presente pesquisa consistiu na elaboração do perfil de competência. Os grupos de foco tiveram em média cinco 
respondentes que discutiram entre si a temática com o incentivo do pesquisador. O resultado do trabalho dos grupos, obtido mediante a análise de conteúdo, considerando as categorias: cognitiva - conhecimento; e comportamentais: habilidade e valores / atitudes que mais apareceram nos grupos apontou para o Perfil de Competência Profissional dos gestores da saúde.

$2^{\circ}$. momento - aplicação de questionários estruturados com 176 indivíduos, escolhidos por conveniência - ocupantes de cargos gerenciais em serviços de saúde - dentre os participantes da primeira etapa da pesquisa, para priorização dos atributos definidos. O questionário foi composto de questões fechadas e abertas. As questões fechadas foram compostas dos atributos definidos no momento anterior para que fossem escolhidos 5 itens e classificados nos níveis da escala Likert: (5) Extrema importância, (4) Muito importante, (3) Bastante importante, (2) Importante e (1) Menor importância. As questões abertas referiram-se sobre a possibilidade de incorporação de novos atributos ao perfil, e a pergunta: No seu curso de graduação em saúde (Medicina, Enfermagem, Farmácia, etc.), havia alguma disciplina que contemplasse o estudo das Competências assinaladas por V.Sa. Como prioritárias para seu desempenho como Gestor/Gerente? A análise dos dados obtidos nas questões fechadas foi feita com uso do software Sphinx, com a tabulação das respostas, permitindo a avaliação da percepção dos respondentes.

\section{RESULTADOS OBTIDOS}

\section{$1^{\circ}$. momento - identificação e definição dos atributos}

O indicador cognitivo, relacionado ao conhecimento, refere-se ao saber teórico, conceitual, fundamental para orientar uma boa prática. Nesta variável foram identificados e definidos dez atributos.

\section{Quadro 3 - Definição das variáveis relacionadas ao Conhecimento}

\begin{tabular}{|c|c|}
\hline CONHECIMENTO & DEFINIÇÃO \\
\hline $\begin{array}{l}\text { Área / Setor de Saúde } \\
\text { (políticas, sistema, } \\
\text { mercado) }\end{array}$ & $\begin{array}{l}\text { Conhecimentos de cunho estratégico sobre o mercado/sociedade no qual a } \\
\text { Empresa se insere, incluindo clientes, concorrentes, fornecedores e parceiros. }\end{array}$ \\
\hline $\begin{array}{l}\text { Administração/ } \\
\text { Finanças/legislação }\end{array}$ & $\begin{array}{l}\text { Conhecimentos pertinentes às áreas de administração e finanças, incluindo } \\
\text { custos, bem como legislação, especialmente trabalhista e comercial. }\end{array}$ \\
\hline $\begin{array}{l}\text { Planejamento } \\
\text { Estratégico e } \\
\text { Operacional }\end{array}$ & $\begin{array}{l}\text { Conhecimento de Modelos e Processos de Planejamento, envolvendo desde } \\
\text { o Diagnóstico, Definição de Prioridades até o Monitoramento/Avaliação, } \\
\text { para orientar a adequada construção de Planos de Ação para a Organização. }\end{array}$ \\
\hline Gestão de pessoas & $\begin{array}{l}\text { Conhecimentos sobre administração de recursos humanos, principais } \\
\text { sistemas de pessoal, como: planejamento de } \mathrm{RH} \text {, seleção/suprimento, } \\
\text { treinamento, carreira, avaliação de desempenho e recompensa. }\end{array}$ \\
\hline Técnico Específico & Conhecimentos técnicos próprios de sua área de formação específica. \\
\hline Informática & $\begin{array}{l}\text { Conhecimento sobre o uso do computador, redes, internet, bem como dos } \\
\text { principais softwares de sua área de atuação. }\end{array}$ \\
\hline $\begin{array}{l}\text { Processo de Tomada de } \\
\text { Decisão }\end{array}$ & Conhecimento de métodos/técnicas que facilitem a Tomada de Decisão. \\
\hline Gestão de Qualidade & $\begin{array}{l}\text { Conhecimento da teoria básica bem como dos processos relacionados com o } \\
\text { funcionamento de sistemas de qualidade total. }\end{array}$ \\
\hline $\begin{array}{c}\text { Psicologia } \\
\text { Organizacional }\end{array}$ & $\begin{array}{l}\text { Conhecimento sobre comportamento das pessoas dentro de uma organização } \\
\text { (comunicação interpessoal, administração de conflitos, negociação, } \\
\text { motivação, formação de equipes). }\end{array}$ \\
\hline $\begin{array}{l}\text { Produto/ mercado de } \\
\text { atuação da empresa/ } \\
\text { instituição }\end{array}$ & $\begin{array}{l}\text { Conhecimento de nível mercadológico sobre os serviços e/ou produtos } \\
\text { fornecidos pela organização. }\end{array}$ \\
\hline
\end{tabular}

Fonte: Elaboração dos grupos pesquisados e sistematizado pelos autores.

O indicador Comportamental A, relacionado à Habilidade, refere-se ao saber fazer, ou seja, a capacidade de aplicar os conhecimentos teóricos. Nesta variável foram identificados e definidos 10 atributos. 
Quadro 4 - Definição das variáveis relacionadas a Habilidades

\begin{tabular}{|c|c|}
\hline HABILIDADE & DEFINIÇÃO \\
\hline Planejamento & $\begin{array}{l}\text { Capacidade de definir e compartilhar metas, estratégias e táticas referentes ao } \\
\text { processo administrativo. }\end{array}$ \\
\hline Organização & $\begin{array}{l}\text { Capacidade de gerenciar o processo administrativo, bem como de definir os } \\
\text { diversos papéis dos membros da equipe, incluindo a distribuição de atividades, } \\
\text { tarefas e responsabilidades. }\end{array}$ \\
\hline Liderança & $\begin{array}{l}\text { Capacidade de influenciar e mobilizar o grupo de trabalho, visando alcançar } \\
\text { objetivos orientados para o bem comum. }\end{array}$ \\
\hline Decisão & $\begin{array}{l}\text { Capacidade de definir ações/tomar atitude após análise de alternativas, e que } \\
\text { levem à resolução do problema/situação examinada. }\end{array}$ \\
\hline $\begin{array}{l}\text { Comunicação/ } \\
\text { saber ouvir }\end{array}$ & $\begin{array}{l}\text { Capacidade de escutar superiores, colaboradores, clientes, fornecedores e } \\
\text { parceiros, dar e receber feedback, bem como de se fazer entender, visando } \\
\text { facilitar a integração entre as pessoas envolvidas e influenciar positivamente o } \\
\text { ambiente de trabalho. }\end{array}$ \\
\hline $\begin{array}{l}\text { Análise e } \\
\text { Síntese }\end{array}$ & $\begin{array}{l}\text { Capacidade de criticar e sintetizar dados e informações sobre processos e } \\
\text { pessoas, a fim de poder reunir elementos objetivos que permitam uma adequada } \\
\text { tomada de decisão. }\end{array}$ \\
\hline $\begin{array}{l}\text { Trabalho em } \\
\text { Equipe }\end{array}$ & $\begin{array}{l}\text { Habilidade pessoal que consiste na capacidade de entrosar-se facilmente com } \\
\text { os demais membros da equipe, negociar e resolver conflitos, e de converter-se } \\
\text { em fator de integração do time como um todo, com ênfase na excelência das } \\
\text { relações interpessoais. }\end{array}$ \\
\hline $\begin{array}{l}\text { Criatividade / } \\
\text { Inovação }\end{array}$ & $\begin{array}{l}\text { Capacidade de gerar novas idéias (Criatividade), bem como de promover sua } \\
\text { implementação (Inovação. }\end{array}$ \\
\hline Execução & $\begin{array}{l}\text { Capacidade de pôr em prática os planos de ação elaborados, visando a efetiva } \\
\text { consecução dos resultados pretendidos. }\end{array}$ \\
\hline $\begin{array}{l}\text { Inspiração e } \\
\text { Motivação da } \\
\text { Equipe }\end{array}$ & $\begin{array}{l}\text { Capacidade do líder de criar condições propiciadoras de inspiração e motivação } \\
\text { para sua equipe, na busca constante do moral elevado do grupo. }\end{array}$ \\
\hline
\end{tabular}

Fonte: Elaboração dos grupos pesquisados e sistematizado pelos autores.

O indicador comportamental - b, que se refere à atitude, significa querer ser/fazer a partir da decisão e motivação pessoal, reflete os valores do indivíduo. Nesta variável foram identificados 10 atributos. 
Quadro 5 - Definição das variáveis relacionadas a Atitudes

\begin{tabular}{|c|c|}
\hline ATITUDE & DEFINIÇÃO \\
\hline Ético & $\begin{array}{l}\text { Respeito absoluto pelo outro, honestidade e justiça nas decisões, e coerência entre o } \\
\text { discurso e a prática. }\end{array}$ \\
\hline Autoconfiante & $\begin{array}{l}\text { Consciência de suas próprias limitações (humildade) e de suas fortalezas (confiança), } \\
\text { passando uma postura de segurança e equilíbrio para sua equipe. }\end{array}$ \\
\hline Determinado & $\begin{array}{l}\text { Busca incessante das condições necessárias para superar desafios e alcançar resulta- } \\
\text { dos, a nível pessoal e profissional. }\end{array}$ \\
\hline Flexível & $\begin{array}{l}\text { Abertura para ouvir/aceitar opiniões diferentes, bem como para perceber as constan- } \\
\text { tes transformações geradoras da necessidade de mudanças organizacionais. }\end{array}$ \\
\hline Responsável & $\begin{array}{l}\text { Resposta, em nível ótimo, ao conjunto de Atribuições do Cargo, com elevado grau de } \\
\text { correspondência às expectativas da Organização em relação à sua pessoa. }\end{array}$ \\
\hline $\begin{array}{l}\text { Servidor/ } \\
\text { Cuidadoso }\end{array}$ & Consciência da importância do Servir/ Cuidar dos liderados e dos clientes/usuários. \\
\hline Comprometido & $\begin{array}{l}\text { Compromisso e envolvimento com a Missão, Negócio e Resultados institucionais, bem } \\
\text { como com as Pessoas da Organização. }\end{array}$ \\
\hline Auto-motivado & $\begin{array}{l}\text { Entusiasmo em nível elevado, evidenciado na postura corajosa de superação dos } \\
\text { desafios do dia-a-dia. }\end{array}$ \\
\hline Visionário & $\begin{array}{l}\text { Antevisão de cenários (sonhos) para onde deseja levar a Organização e a Equipe e } \\
\text { disposição para compartilhar estes sonhos com seu grupo de trabalho. }\end{array}$ \\
\hline $\begin{array}{l}\text { Aprendiz/ } \\
\text { Educador }\end{array}$ & $\begin{array}{l}\text { Disponibilidade para Querer aprender sempre (busca do auto-desenvolvimento), bem } \\
\text { como Preocupação com o desenvolvimento de todos da equipe (papel educacional). }\end{array}$ \\
\hline
\end{tabular}

Fonte: Elaboração dos grupos pesquisados e sistematizado pelos autores.

Observa-se, resgatando Galer, Vriesendorp e Ellis (2005) que consideram as competências (a) gerenciais planejamento, organização de recursos, implementação e execução do trabalho e monitoração dos resultados; e (b) de liderança - explorar, focalizar, alinhar e mobilizar o pessoal, e inspirar e motivar a equipe, que os pesquisados escolheram dentre os dez conhecimentos mais importantes do gestor líder, de acordo com a descrição dos atributos, aqueles que estão mais relacionados à gerência como planejamento, administração e processo de decisão. O atributo Psicologia Organizacional sinalizaria para a competência de liderança. Resgatando Moreira et al (1997) verifica-se sintonia com a dimensão técnica que tem como principal atributo o conhecimento específico de uma área de conhecimento.

Com relação aos indicadores comportamentais referentes a habilidades e atitudes, verifica-se bastante semelhança com as referências bibliográficas apresentadas tanto para as competências gerenciais como para as de liderança.

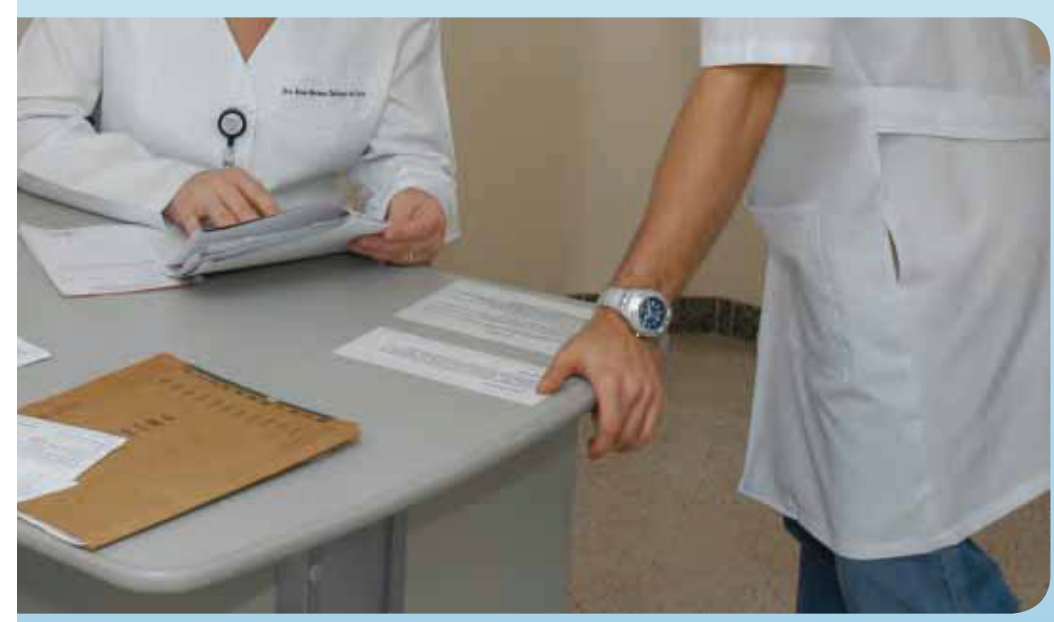


Existe semelhança com Moreira et al (1997) no que se refere às dimensões: administrativa - habilidade de planejamento e organização; psicossocial - habilidade de interagir de forma construtiva na dinâmica dos inter-relacionamentos; e dimensão política do exercício do poder - habilidade de tomar decisão e a capacidade de influenciar e mobilizar o grupo de trabalho.

De acordo com os componentes do perfil do gestor na atualidade estabelecido por Oderich (2005) in Ruas (2005) verificou-se, considerando o atributo e sua descrição: visão sistêmica e estratégica / planejamento estratégico e operacional, domínio pessoal / auto-confiante, capacidade de trabalhar em equipe / trabalho em equipe, criatividade, flexibilidade, capacidade de inovação, comportamento ético e capacidade de aprender, de liderar e educar / aprendiz / educador.

Considerando o modelo de Heifetz (1999), verificou-se semelhança principalmente com os atributos: conhecimento do contexto; habilidade de saber ouvir, criatividade e inspiração; e valores / atitudes como aumento da capacidade de adaptação ao sistema social/ flexibilidade, paixão pela sabedoria/ aprendizeducador, exame dos valores/ postura ética.

Na primeira etapa da pesquisa foi identificado e definido o perfil de competência profissional do gestor da área de saúde. A sistematização dos dados obtidos na survey foi feita pelos pesquisadores. Observase que o perfil elaborado pelos pesquisados tem sintonia com pesquisas anteriores realizadas, citadas na fundamentação teórica deste trabalho, o que sinaliza para o fato de que o gestor da área de saúde, oriundo do programa de PDL, já estaria incorporando os conceitos de competência ao seu discurso.

\section{$2^{\circ}$. Momento: priorização dos atributos}

O segundo momento da pesquisa teve como objetivo priorizar os atributos mais importantes na visão dos pesquisados do perfil de competência gerencial sistematizado pelos pesquisadores.

\section{CARACTERIZAÇÃO DOS PESQUISADOS}

\subsection{Caracterização dos pesquisados}

\section{Tabela 1 - Formação Acadêmica}

\begin{tabular}{lcc}
\hline Formação Acadêmica & Qt. cit. & Freq. \\
\hline Medicina & 71 & $40,3 \%$ \\
Enfermagem & 41 & $23,3 \%$ \\
Odontologia & 4 & $2,3 \%$ \\
Farmácia & 28 & $15,9 \%$ \\
Fisioterapia & 3 & $1,7 \%$ \\
Terapeuta Ocupacional & 2 & $1,1 \%$ \\
Nutrição & 7 & $4,0 \%$ \\
Outras & 20 & $11,4 \%$ \\
Total & 176 & $100,0 \%$ \\
\hline
\end{tabular}

\begin{tabular}{lcc}
\hline Pós-graduação & Qt. cit & Freq. \\
\hline Especialização & 128 & $72,7 \%$ \\
Mestrado & 21 & $11,9 \%$ \\
Doutorado & 8 & $4,5 \%$ \\
Nenhuma & 19 & $10,8 \%$ \\
TOTAL CIT. & 176 & $\mathbf{1 0 0} \%$ \\
\hline
\end{tabular}

Fonte: Pesquisa direta

Os pesquisados são em sua maioria: médicos (40,3\%), seguidos de enfermeiros (23,3\%) e farmacêuticos $(15,9 \%)$ o que apontaria a realidade da ocupação dos postos de gestão na área de saúde. Os respondentes em sua maioria possuem cursos de especialização $(72,7 \%)$. 
Tabela 3 - Caracterização quanto ao sexo

\begin{tabular}{lrc}
\hline Sexo & Qt. cit & Freq. \\
\hline Masculino & 72 & $40,9 \%$ \\
Feminino & 104 & $59,1 \%$ \\
TOTAL & 176 & $100 \%$ \\
\hline Fonte: Pesquisa direta & &
\end{tabular}

Os investigados estão distribuídos entre indivíduos de ambos os sexos.

Tabela 4 - Local de trabalho

\begin{tabular}{|c|c|c|}
\hline Local de Trabalho & Qt. cit & Freq. \\
\hline Hospital & 71 & $40,3 \%$ \\
\hline Órgão do Governo & 48 & $27,3 \%$ \\
\hline $\begin{array}{l}\text { Convênio/Cooperativa de } \\
\text { classe }\end{array}$ & 39 & $22,2 \%$ \\
\hline Particular & 18 & $10,2 \%$ \\
\hline TOTAL CIT. & 176 & $100 \%$ \\
\hline
\end{tabular}

Tabela 5 - Cargo / função

\begin{tabular}{lcr}
\hline Cargo/Função & Qt. cit & Freq. \\
\hline Coordenador & 52 & $29,5 \%$ \\
Diretor & 39 & $22,2 \%$ \\
Gerente & 30 & $17,0 \%$ \\
Chefe de Serviço & 28 & $15,9 \%$ \\
Chefe de Setor & 5 & $2,8 \%$ \\
Supervisor & 14 & $8,0 \%$ \\
Técnico & 8 & $4,5 \%$ \\
Não especificado & 0 & $0,0 \%$ \\
TOTAL CIT. & $\mathbf{1 7 6}$ & $\mathbf{1 0 0 , 0} \%$ \\
\hline
\end{tabular}

Fonte: Pesquisa direta

Os pesquisados trabalham em sua maioria em hospitais $(40,3 \%)$, órgãos do governo $(27,3 \%)$ e cooperativas de classe (22,2\%), exercendo atividades de gerência.

Tabela 6 - Tempo de serviço

\begin{tabular}{lcc}
\hline Tempo de serviço & Qt. cit & Freq. \\
\hline Menos de 5 anos & 22 & $12,5 \%$ \\
De 5 a 15 anos & 47 & $26,7 \%$ \\
De 15 a 25 anos & 59 & $33,5 \%$ \\
Mais de 25 anos & 48 & $27,3 \%$ \\
TOTAL CIT. & $\mathbf{1 7 6}$ & $\mathbf{1 0 0 \%}$ \\
\hline
\end{tabular}

Tabela 7 - Experiência gerencial

\begin{tabular}{lcc}
\hline Experiência Gerencial & Qt. cit & Freq. \\
\hline Menos de 2 anos & 21 & $11,9 \%$ \\
De 2 a 5 anos & 43 & $24,4 \%$ \\
De 5 a 10 anos & 48 & $27,3 \%$ \\
Mais de 10 anos & 64 & $36,4 \%$ \\
TOTAL CIT. & $\mathbf{1 7 6}$ & $\mathbf{1 0 0 \%}$ \\
\hline
\end{tabular}

Fonte: Pesquisa direta

Os respondentes são profissionais com mais de 5 anos de tempo de serviço e de exercício de atividade gerencial. Os pesquisados podem ser caracterizados em sua maioria como profissionais da área de medicina, enfermagem e farmácia, com cursos de especialização exercendo a mais de 5 anos cargos de gerência em hospitais. 


\subsection{Perfil de Competência Gerencial}

A validação do perfil de competência e priorização dos atributos registra os resultados que se seguem.

Tabela 8 - Conhecimentos

\begin{tabular}{l|c}
\hline Conhecimentos & $\%$ \\
\hline Planejamento estratégico e & 21,0 \\
operacional & 13,0 \\
Setor de saúde & 11,0 \\
Psicologia organizacional & 10,5 \\
Gestão de pessoas & 10,0 \\
Técnico específico & 10,0 \\
Processo de tomada de decisões & 10,0 \\
Gestão da qualidade & 9,0 \\
Administração/finanças & 3,0 \\
Informática & 2,5 \\
Produto & 100,0 \\
\hline
\end{tabular}

Fonte : Pesquisa direta

Foi considerado o conhecimento mais importante o planejamento estratégico e operacional, seguido de conhecimentos sobre o setor de saúde e psicologia organizacional. Foram considerados no mesmo patamar de importância os conhecimentos de gestão de pessoas, técnico específico, processo de tomada de decisão e gestão da qualidade.

Foi considerado o conhecimento menos importante o mercadológico sobre os serviços e/ou produtos fornecidos pela organização.

Os depoimentos corroboram a necessidade das grades curriculares acadêmicas contemplarem disciplinas do campo gerencial:

- "Infelizmente a universidade [formação acadêmica] se mostra bastante limitada a questões técnicocientífica não se estendendo as necessidades de exigência do mercado"(enfermeira);

- "A academia é excessivamente tecnicista, não correspondendo as demandas do mercado e da sociedade. Falta de foco na aprendizagem baseada em problemas. Existem poucas atividades que gerem avaliações de atitude e habilidades" (farmacêutico);

- "O curso curricular não nos prepara para assumir cargos de gestão" (médico);

- "A universidade deve preparar seus universitários para direção e gestão" (médico);

- "Necessidade de incorporar uma nova mentalidade administrativa aos profissionais de saúde" (médico);

- "A exemplo do que já ocorre em alguns cursos da área de saúde, como na enfermagem, há a clara necessidade de se introduzir o tema Gestão em Saúde na grade curricular de todos os cursos"(médico);

- "Os profissionais de enfermagem são melhor preparados desdea graduação, para a gestão"(enfermeiro);

- "Infelizmente o meu curso de graduação foi muito relacionado a área de odontologia, existia na época uma visão tecnicista de graduação que sequer preocupava-se com o setor público, nos formaria para sermos doutores de consultórios particulares" (dentista).

Observa-se que independentemente da formação os respondentes reconhecem que a academia prepara técnicos especialistas, havendo necessidade de incorporar novas disciplinas ao currículo como vem acontecendo com o curso de Enfermagem.

A valorização do planejamento estratégico e operacional pode sinalizar que a área de saúde está carente deste conhecimento e ao mesmo tempo consciente de sua necessidade. 
Tabela 9 - Habilidades

\begin{tabular}{l|c}
\hline \multicolumn{1}{c|}{ Habilidades } & $\%$ \\
\hline Liderança & 21,0 \\
Organização & 14,0 \\
Comunicação/saber ouvir & 14,0 \\
Planejamento & 12,0 \\
Decisão & 10,0 \\
Trabalho em equipe & 9,0 \\
Execução & 7,0 \\
Inspiração e Motivação & 6,0 \\
Análise e síntese & 4,0 \\
Criatividade / Inovação & 3,0 \\
Total & 100,0 \\
\hline
\end{tabular}

Fonte: Pesquisa direta

As habilidades consideradas mais importantes foram: liderança, organização, comunicação / saber ouvir, planejamento e decisão.

Nos depoimentos livres verificou-se que os cursos da área de saúde, tradicionalmente, priorizam o componente técnico:

- "O curso [de medicina] não prepara os profissionais como seres humanos" (médico);

- "Há que se considerar como prioridade o investimento nas relações humanas desde o período de formação dos profissionais, para o sucesso das ações desenvolvidas pelas instituições" (médico);

- "O curso é extremamente técnico, com disciplinas voltadas para tornar o aluno um técnico competente, não existindo flexibilidade para estudar ou conhecer matérias que desenvolvessem a capacidade social e humana" (farmacêutico);

- "No curso de graduação apenas aprendemos a ser técnicos e não sabemos nada sobre a realidade que iremos encontrar lá fora, inclusive a de lidar com pessoas de vários níveis de conhecimento, crença e raças; apenas na graduação o nosso mundo se concentra na faculdade e não se faz um trabalho de conscientização, afinal todos somos humanos, temos problemas, conflitos, contas a pagar, vivemos no mundo e não a parte dele" (fisioterapeuta).

Os depoentes manifestam a necessidade do desenvolvimento de "habilidades humanas" e um médico argumenta que "liderar, antever, sonhar, motivar, decidir, agir e planejar, são atitudes inerentes a todos os profissionais de saúde, gestores, e deveriam fazer parte da grade curricular". Observa-se o reconhecimento de que algo está mudando no depoimento de outro médico que declara que "somente com o advento da humanização da saúde, os cursos e a própria atuação de nós profissionais dirigiu-se para o âmbito do ser humano, suas relações, aspirações, defeitos, qualidades, etc. agora é nossa chance". 
Tabela 10 - Atitudes

\begin{tabular}{l|c}
\hline \multicolumn{1}{c}{ Atitudes / Valores } & $\%$ \\
\hline Ética & 22,0 \\
Comprometido & 16,0 \\
Flexível & 14,0 \\
Determinado & 11,0 \\
Responsável & 10,0 \\
Aprendiz/educador & 10,0 \\
Auto-confiante & 6,0 \\
Auto-motivado & 4,0 \\
Visionário & 4,0 \\
Servidor/Cuidadoso & 3,0 \\
Total & 100,0 \\
\hline
\end{tabular}

Fonte: Pesquisa direta

Com relação a atitudes o grande destaque foi a atitude ética no exercício profissional, ou seja, respeito absoluto pelo outro, honestidade e justiça nas decisões, e coerência entre o discurso e a prática, seguida de compromisso, flexibilidade, determinação, responsabilidade e postura de aprendiz e educador.

\section{CONSIDERAÇÕES PROVISÓRIAS}

As novas demandas sociais fazem emergir a necessidade de construção de novos perfis gerenciais que estrategicamente possam dar conta e agregar valor a realidade. Nesta situação a aprendizagem e o desenvolvimento de lideranças tornam-se fundamentais. Na área de saúde os processos de aprendizagem para desenvolvimento de lideranças estão acontecendo para preenchimento desta lacuna. A presente pesquisa revelou a percepção dos pesquisados sobre perfil de competência profissional ideal para o exercício de atividades gerenciais na área de saúde com destaque para os atributos relacionados ao conhecimento e habilidade de planejamento estratégico e operacional, habilidade de liderança e atitude ética. O pressuposto estabelecido de que os alunos oriundos de processos de aprendizagem são capazes de definir um perfil de competência gerencial em sintonia com o estado da arte da Administração foi comprovado.

Os limites do trabalho, e que remete a uma reflexão, referem-se à verificação da aplicação prática nas situações de trabalho dos conhecimentos adquiridos nos processos de aprendizagem.

Outro tema que necessita ser explorado refere-se à dimensão política da competência (MOREIRA et al, 1997, p.14) extrapolando o simples exercício do poder, o grau de autonomia e decisão e a capacidade de influência nas ações da empresa, para ver as questões da saúde no âmbito da sociedade como um todo e contemplando o conjunto dos cidadãos.

\section{REFERÊNCIAS BILIOGRÁFICAS}

BALDWIN, Timothy et al. Desenvolvimento de habilidades gerenciais. Rio de janeiro: Elsevier, 2008.

BAND, William A. Competências críticas. Rio de Janeiro: Campus, 1997.

BITENCOURT, Claudia Cristina. A gestão de competências gerenciais - a contribuição da aprendizagem organizacional. Tese de doutorado. Universidade Federal do Rio Grande do Sul. Escola de Administração. Programa de pós-graduação. Porto Alegre, 2001.

BRITO, Lydia Maria Pinto. Gestão de competências, gestão do conhecimento e organizações de aprendizagem: instrumento de apropriação pelo capital do saber do trabalhador. Fortaleza: UFC, 2004. 
BRITO, Lydia Maria Pinto. Práticas de pesquisa em gestão de pessoas. Fortaleza: UFC, 2007.

COOPER, Donald R.,SCHINDLER, Pámela S. Métodos de Pesquisa em Administração. Porto Alegre:Bookman, 2003.

DUTRA, Joel de Souza (org.). Gestão por Competências. São Paulo: Gente,2002.

FLEURY, Afonso e FLEURY, Maria Tereza. Estratégias Empresariais e Formação de Competências. São Paulo: Atlas, 2001.

FLEURY, M. T. L; OLIVEIRA JUNIOR, M.D M. Gestão estratégica do conhecimento. São Paulo: Atlas, 2001.

FLANNERY, Thomas P., HOFRICHTER, David e PLATTEN, Paul E. Pessoas, Desempenho e Salários. São Paulo: Futura, 1997

FLICK, Uwe. Uma introdução a pesquisa qualitativa.Porto Alegre: Bookman,2004.

GALER, Joan Bragar, VRIESENDORP, Sylvia e ELLIS, Alison. Managers who lead.Cambridge: Management Sciences for Healt, 2005.

GRAMIGNA, Maria Rita - Modelo de Competências e Gestão de Talentos. São Paulo: Makron Books, 2002.

HAMEL, Gary e PRAHALAD, C.K. Competindo pelo Futuro - estratégias inovadoras para obter o controle do seu setor e criar mercados de amanhã. São Paulo: Campus, 1995.

LE BOTERF, Guy. Desenvolvendo a competência dos profissionais. Porto Alegre: Artmed, 2003.

MOREIRA, Claudia Maria M. at al. Habilidades Gerenciais. Rio de Janeiro: SENAC,1997.

FLANNERY,Thomas P., HOFRICHTER, David, e PLATTEN, Paul E. Pessoas, desempenho e salário. São Paulo:Futura, 1997.

PERRENOUD, Philippe. Avaliação - da excelência à regulação das aprendizagens entre duas lógicas. Porto Alegre: Artmed,1999.

PERRENOUD, Philippe e outros. As competências para ensinar no século XXI, a formação dos professores e o desafio da avaliação. Porto Alegre: Artmed,2002.

PICARELLI FILHO, Vicente. Remuneração por habilidade e por competência.São Paulo:Atlas, 1997.

PORTER, Michael E. e TEISBERG, Elizabeth Olmsted. Repensando a saúde. Porto Alegre: Bookman, 2007.,

RESENDE, Enio. O livro das Competências.Rio de Janeiro: Qualitymark, 2000.

RIOS, Terezinha Azeredo. Ética e competência. São Paulo:Cortez, 2006.

RUAS, Roberto et Al. Aprendizagem organizacional e competências. Porto Alegre: Bookman, 2005.

YAMAMOTO, Edson. Os novos médicos administradores.São Paulo:Futura,2001.

ZARIFIAN, Philippe. Objetivo Competência - por uma nova lógica. São Paulo: Atlas,2001.

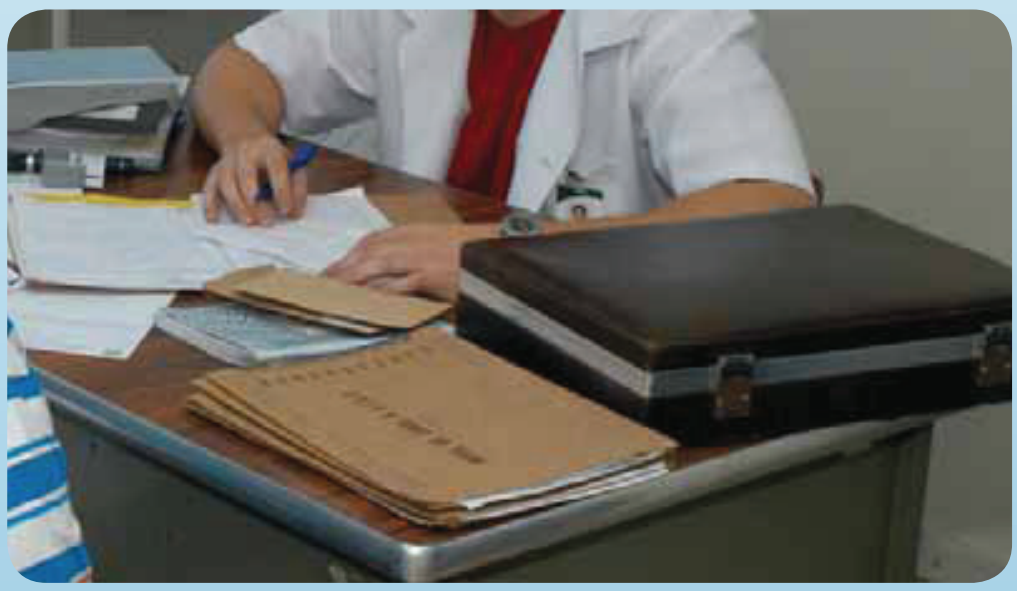

